\title{
ПОНИМАНИЕ СПРАВЕДЛИВОСТИ ЛЮДЬМИ С РАЗНЫМ УРОВНЕМ ЧУВСТВИТЕЛЬНОСТИ К ЕЕ НАРУШЕНИЮ
}

\author{
Адамян А.А. (Национальный исследовательский университет \\ «Высшая школа экономики», Москва, Россия) \\ anna.a.adamyan@yandex.ru

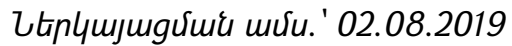

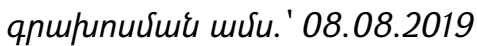

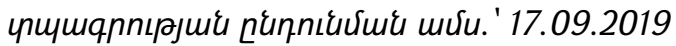

В статье рассматривается соотношение уровня чувствительности к справедливости с обыденными представлениями о справедливости. Чувствительность к справедливости понимается как готовность человека воспринимать несправедливость и его эмоциональные, когнитивные и поведенческие реакции на нее. Участники исследования ( $\mathrm{N}=98$; средний возраст $=18,6, \mathrm{SD}=1,2)$ давали ассоциации к понятию «справедливость». Ассоциации группировались в соответствии с категориями обыденных представлений о справедливости, выделяемыми в социальной психологии для российского общества. Вне зависимости от уровня чувствительности к справедливости самой распространенной категорией ассоциаций является «возможность верить человеку». Испытуемые с высокой чувствительностью с позиции жертвы по сравнению с группой с низкой чувствительностью чаще ассоциируют справедливость со следованием моральным нормам и реже с понятием воздаяния (объективности). Для испытуемых с высокой чувствительностью с позиции свидетеля справедливость также в меньшей мере ассоциируется С понятием объективности. В то время как в целом справедливость для всех участников ассоциируется с категориями из области межличностного взаимодействия, меньшая чувствительность к справедливости связана с более рациональным пониманием справедливости.

Ключевые слова: чувствительность к справедливости, обыденные представления.

Понятие чувствительности к справедливости (ЧС) было предложено М. Шмиттом для описания черты личности (диспозиции), характеризующей восприимчивость человека к ситуациям нарушения справедливости: готовность видеть несправедливость в жизненных ситуациях, интенсивность эмоциональных реакций, стремление к восстановлению справедливости. В зависимости от позиции, которую человек занимает в ситуации несправедливости, выделяют чувствительность к справедливости с позиции жертвы, свидетеля, бенефициара, нарушителя (Ч понимается как характеристика, не связанная с содержанием представлений о справедливости. Согласно исследованиям, проведенным в Германии, ЧС с позиции 
жертвы не коррелирует с нормами дистрибутивной справедливости, ЧС с позиций свидетеля и бенефициара не связана с отношением к норме беспристрастности и лишь умеренно коррелируют с позицией в отношении норм равенства и учета потребностей [6]. Авторы интерпретируют полученный результат как свидетельство независимости ЧС индивида от конкретного содержания норм справедливости.

В то же время представления о справедливости не ограничиваются приверженностью тем или иным нормам, само семантическое поле ассоциаций, в котором существует это понятие, также различается у отдельных людей. На уровне культуры существуют устойчивые категории обыденных представлений о справедливости, которые по-разному находят отражение в сознании представителей этой культуры. Рассматривая историю развития представлений о справедливости в России, О.А. Гулевич [2,3] выделяет четыре значения этого слова, которые устойчиво сложились в России к началу 20-го века. Эти значения: истина как соответствие реальным событиям или фактам, воздаяние должного, хорошее отношение к людям (как черта личности, предполагающая равное отношение ко всем и готовность к бескорыстной помощи), равенство прав (значение, заложенное в юридическом понимании справедливости). Для выяснения актуальных коллективных представлений о справедливости были проведены исследования [3,4], в результате которых были выделены значения слова «справедливость», часть из которых совпадает с теми, которые оформились в России еще в дореволюционный период (например, «воздаяние по заслугам», «хорошее отношение к людям»), а другая часть стала результатом социального дискурса 20-го века. Были определены категории ассоциаций к понятию «справедливость», соотносимые с источниками справедливости и конкретными ее критериями: “следование моральным нормам», «следование правовым нормам», "воздаяние по заслугам», "хорошее отношение к людям», «возможность верить человеку» (трансформация значения «истина» с добавлением субъективного компонента), “равенство позиций» (объединяющее равенство прав и результатов), «личная активность» (собственная активность по защите своих интересов).

До сих пор в исследованиях не рассматривался вопрос о том, как ЧС соотносится с обыденными представлениями о справедливости. Можно предположить, что семантическое поле ассоциаций к слову “справедливость» может быть связано со степенью значимости этого понятия для человека и со степенью его восприимчивости к нарушению справедливости. Представляет интерес вопрос о том, различаются ли обыденные представления о справедливости у людей с различными уровнями ЧС: например, связана ли высокая ЧС с фокусом на морали, на соблюдении правил соответствия между вкладом и результатом или на отношениях между людьми.

С целью ответить на данный вопрос было проведено исследование обыденных представлений о справедливости, выделяемых на основании соотнесения ассоциаций к слову «справедливость» и категорий обыденных представлений, 
сорормированных в исследовании О.А. Гулевич [3], в соотношении с показателями каждой из шкал ЧС.

Участниками исследования были студенты НИУ «ВШЭ», добровольцы ( $\mathrm{N}=98$; средний возраст $=18,6, \mathrm{SD}=1,2 ;$ среди них 81 девушка).

Процедура исследования обыденных представлений о справедливости заключалась в анализе набора из трех ассоциаций, которые давал каждый из респондентов к слову “справедливость». Ассоциации соотносились с категориями обыденных представлений о справедливости, выделенными в исследовании О.А. Гулевич [3]. Категории включают: следование моральным нормам, следование правовым нормам, воздаяние по заслугам, хорошее отношение к людям, возможность верить человеку, равенство позиций, личная активность. Были выделены группы респондентов с высоким и низким уровнем каждого из измерений ЧС: результаты считались высокими либо низкими в случае, если они выходили за пределы одного стандартного отклонения по соответствующей шкале. Для каждой из групп подсчитывалось количество участников, чьи ассоциации относились к каждой из категорий обыденных представлений. Затем с помощью критерия Хи-квадрат ${ }^{1}$ проводилась оценка значимости различий между группами.

Наиболее распространенной категорией для всех групп вне зависимости от уровней разных аспектов ЧС являлась “возможность верить человеку». Значимые различия были обнаружены между группами с высоким и низким уровнем Чжертв для категорий «следование моральным нормам» $\left(\chi^{2}(1, N=29)=3.4, p<0.05\right.$; высокий уровень Чжертв связан с большим количеством ассоциаций из категории) и «воздаяние по заслугам» $\left(\mathrm{X}^{2}(1, \mathrm{~N}=25)=3.9, \mathrm{p}<0.05\right.$; низкий уровень связан с большим количеством ассоциаций из категории), а также между высоким и низким уровнем Чсвид для категории «воздаяние по заслугам» $\left(\mathrm{X}^{2}(1, \mathrm{~N}=17)=3.9, \mathrm{p}<0.05\right.$; низкий уровень связан с большим количеством ассоциаций).

К категории «воздаяние по заслугам» относились ассоциации «объективность» и «беспристрастность». Таким образом, в ней фиксированы не конкретные правила распределения или проведения процедуры, а сам факт понимания справедливости как некого правила, соответствия заслуженного, полагающегося и реально получаемого (в виде конкретных благ или формы отношения). Категория «следование моральным нормам» включала «совесть», «мораль», «нравственность», «порядочность». Понимание справедливости в терминах соответствия некоторым внешним правилам распределения благ или проведения процедур более характерно для людей с низким уровнем Чжертв и Чсвид. Такой вариант понимания справедливости -

\footnotetext{
1 Так как ожидаемые значения лежали в пределах от 5 до 9, использовался хи-квадрат с поправкой Йейтса. Для исследования групп Чжертв и распространенности категории «следование моральным нормам» применялся точный критерий Фишера, так как одно из ожидаемых значений было меньше 5. Таблицы значений критериев приведены в приложении.
} 
как объективности, беспристрастности - менее связан с возможными эмоциональными переживаниями: нарушение некоторого фрормального порядка вещей не создает пространства для переживаний, диалог с другим тут так же отсутствует, так как во главу угла ставится принцип, а не отношения ${ }^{2}$ В то же время восприятие справедливости в одном ряду с категориями нравственности, порядочности и совести характерно для высокого уровня Чжертв. Можно предположить, что в этой ситуации образ другого, занимающего позицию безнравственности, бессовестности выступает очень ярко, вызывая сильные эмоции в моменте и тенденцию размышлять о ситуации в дальнейшем. Другой не просто нарушил определенный порядок вещей, он переступил через нравственный закон, при этом жертва несправедливости оказывается в позиции безвинного страдальца, на стороне которого высшие представления о справедливости. Интересно, что значимые различия наблюдаются только для групп с высокой и низкой Чжертв, но не для других измерений ЧС. Сфокусированность на моральном облике другого характерна для острого переживания ситуации из позиции жертвы, которая предполагает заботу о своих собственных правах и выгодах, в то время как выраженность ЧС других измерений, согласно исследованиях М. Шмитта с коллегами, располагающих к просоциальному поведению, не связана с восприятием ситуаций несправедливости и нарушителей в этих терминах. Размышления в категориях высокой морали, таким образом, связаны с переживанием обиженности и обделенности, но не способствуют большей заботе о ближнем.

Ограничением данного исследования является возраст и гендерный состав участников. Перспективы дальнейших исследований лежат в области охвата более широких групп испытуемых. Знание о том, какие представления о справедливости связаны с менее выраженными негативными переживаниями относительно нарушения справедливости, может представлять практический интерес для области психологического консультирования. В то же время с позиций поддержания социальной справедливости может быть интересен вопрос о том, какие показатели ЧС в сочетании с представлениями о справедливости соотносятся со стремлением к восстановлению справедливости.

\section{Литература}

1. Адамян А. А., Нартова-Бочавер С. К., Шмитт М. Опросник “Чувствительность к справедливости": валидизация на русскоязычной выборке //Психологический журнал. - 2018. - Т. 39. - №. 4. - С. 105-116

2. Гулевич О.А. Социальная психология справедливости. М.: Изд-во “Институт психологии РАН”, 2011

2 Ассоциация «гуманность», в исследовании О.А. Гулевич также вошедшая в категорию «воздаяние по заслугам», участниками данного исследования не использовалось. 
3. Гулевич О.А. Структурно-фрункциональная модель регуляции обыденных представлений о справедливости// Диссертация на соискание степени доктора психологических наук, 2012.

4. Гулевич О. А., Голынчик Е. О. Обыденные представления о справедливости //Вопросы психологии. - 2003. - №. 5. - С. 80-92.

5. Нартова-Бочавер С.К., Астанина Н.Б. Психологические проблемы справедливости в зарубежной персонологии: теории и эмпирические исследования // Психологический журнал. 2014. № 1.

6. Baumert A., Schmitt M. Justice Sensitivity // Handbook of social justice theory and research / Eds.C. Sabbagh \& M. Schmitt . New York, NY: Springer, 2016. P.161180

\section{UNDERSTANDING OF JUSTICE IN PEOPLE WITH DIFFERENT LEVELS OF SENSITIVITY TO ITS VIOLATION}

Adamyan A. A. (National Research University Higher School of Economics, Moscow, Russia)

The article discusses relationships between justice sensitivity and common attitudes to justice. Justice sensitivity is understood as a person's willingness to perceive injustice and his emotional, cognitive and behavioral responses to it. Study participants ( $N=98$; mean age=18.6, SD = 1.2) gave associations to the notion of "justice" and completed Justice Sensitivity Inventory. Associations were grouped according to the categories of common attitudes to justice that are distinguished for Russian society. Regardless of the level of justice sensitivity, the most common category of association is "the ability to believe a person". Subjects with high justice sensitivity from victim's perspective associated justice with morality more often, and with objectivity less often than the group with low victim justice sensitivity. For subjects with high justice sensitivity from witness's perspective, justice is also less associated with the notion of objectivity.

Keywords: sensitivity to justice, routine views. 